\title{
Uncoupling of DNA excision repair and nucleosomal unfolding in poly (ADP-ribose)-depleted mammalian cells
}

\author{
Mathis, Georg ; Althaus, Felix R
}

\begin{abstract}
The repair of DNA damage in eukaryotic cells is closely coupled with local changes of chromatin structure such that newly synthesized repair patches transiently appear in 'free' DNA domains with increased accessibility to enzymatic and chemical probes. We have isolated these domains from mammalian cells repairing bulky DNA adducts. During the first $3 \mathrm{~h}$ of repair, excision of adducts occurred exclusively in free DNA and was closely linked with the appearance of newly synthesized repair patches. Following depletion of chromatin-bound poly(ADP-ribose), the repositioning of repair patches into these domains was completely blocked, although overall repair patch synthesis was unaltered. Concomitantly, DNA adducts were no longer excised and tended to accumulate in free DNA domains. Our results suggest a tight coupling of the excision step with the formation of free DNA domains by a mechanism involving poly ADP-ribosylation of chromatin proteins
\end{abstract}

DOI: https://doi.org/10.1093/carcin/11.7.1237

Posted at the Zurich Open Repository and Archive, University of Zurich ZORA URL: https://doi.org/10.5167/uzh-154126

Journal Article

Published Version

Originally published at:

Mathis, Georg; Althaus, Felix R (1990). Uncoupling of DNA excision repair and nucleosomal unfolding in poly (ADP-ribose)-depleted mammalian cells. Carcinogenesis, 11(7):1237-1239.

DOI: https://doi.org/10.1093/carcin/11.7.1237 


\section{SHORT COMMUNICATION}

\section{Uncoupling of $\mathbb{D N A}$ excision repair amd mucleosomal unfifoldoing in polly(ADP-ribose)-dlepleted mammanliam cells}

\author{
Georg Mathis and Felix R.Althaus ${ }^{1}$ \\ University of Zürich (Tierspital), Institute of Pharmacology and \\ Biochemistry, Winterthurerstrasse 260, CH-8057 Zürich, Switzerland \\ 'To whom correspondence should be addressed
}

The repair of DNA damage in eukaryotic cells is closely coupled with local changes of chromatin structure such that newly synthesized repair patches transiently appear in 'free' DNA domains with increased accessibility to enzymatic and chemical probes. We have isolated these domains from mammalian cells repairing bulky $\mathbb{D N A}$ adducts. During the first $3 \mathrm{~h}$ of repair, excision of adducts occurred exclusively in free DNA and was closely linked with the appearance of newly synthesized repair patches. Following depletion of chromatin-bound poly(ADP-ribose), the repositioning of repair patches into these domains was completely blocked, although overall repair patch synthesis was unaltered. Concomitantly, DNA adducts were no longer excised and tended to accumulate in free $\mathbb{D N A}$ domains. Our results suggest a tight coupling of the excision step with the formation of free $\mathbb{D N A}$ domains by a mechanism involving poly $A \mathbb{D P}$ ribosylation of chromatin proteins.

In chromatin of mammalian cells, newly synthesized DNA repair patches exhibit a transient micrococcal nuclease hypersensitivity. This hypersensitivity is thought to reflect local disruptions in the tightly packed nucleosomal organization of chromatin, causing exposure of 'free' DNA domains (for review see 1,2). The function of these domains as well as the mechanisms involved in their formation are unknown. We have speculated that the post-translational poly ADP-ribosylation of chromatin proteins might be involved in the formation of free DNA domains in DNA excision repair. Poly ADP-ribosylation is catalyzed by the enzyme poly(ADP-ribose)polymerase (1,3,4; EC 2.4.2.30). Following activation by DNA nicks, this enzyme operates in a strictly processive manner (5). Continuous treatment of living cells with benzamide, a competitive inhibitor of this enzyme $(3,4,6)$, results in the degradation of chromatin-bound ADP-ribose polymers (7) by the enzyme poly(ADP-ribose)glycohydrolase $(3,4)$. Using non-replicating adult rat hepatocytes in primary monolayer culture, we have established conditions for the complete depletion of chromatin-associated poly(ADP-ribose) $(7,8)$. Hepatocytes survive up to 9 days under these conditions and maintain expression of liver-specific functions (8). Thus, poly(ADPribose)-depleted hepatocytes represent a convenient model system to study the role of poly ADP-ribosylation in specific steps of DNA repair.

We have previously shown that unfolded free DNA domains can be isolated from the chromatin of intact mammalian cells by taking advantage of their preferential accessibility to 8-methoxypsoralen (9). Upon intercalation into free DNA domains of living cells, 8-methoxypsoralen can be photoactivated to form bifunctional DNA adducts crosslinking the two DNA strands. Crosslinked (free) DNA domains can then be isolated quantitatively following a denaturation/renaturation treatment and subsequent nuclease $\mathrm{S} 1$ digestion of non-crosslinked DNA strands (for details see 9).

Here we have isolated free DNA domains from non-replicating hepatocytes (9), which had been induced to repair bulky DNA adducts by treatment with a low dose of the ultimate carcinogen $\mathrm{N}$-acetoxy-2-acetylaminofluorene. Figure 1 shows that newly synthesized repair patches, pulse-labeled for an initial $20 \mathrm{~min}$ repair period, gradually accumulate in free DNA domains during subsequent chase periods. This observation is in accordance with previous results based on nuclease probing of chromatin $(1,2)$, or direct isolation of these domains (9).

No repositioning of repair patches into free DNA domains was observed in poly(ADP-ribose)-depleted hepatocytes (7; Figure 1 , legend). This depletion did not affect the overall synthesis of repair patches (Figure 1, legend). Thus, the synthesis and repositioning of repair patches in poly(ADP-ribose)-depleted chromatin of hepatocytes were uncoupled.

Figure 2 provides a comparison of excision activity in total chromatin (Figure 2A) and free DNA (Figure 2B) of poly(ADPribose)-depleted and undepleted hepatocytes. In the first $3 \mathrm{~h}$ of

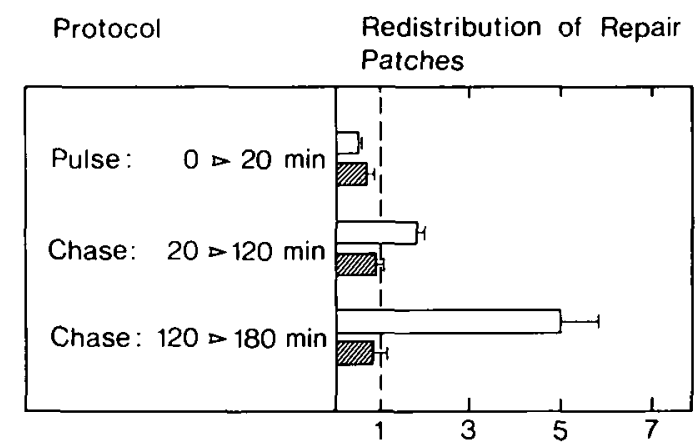

Fig. 1. Redistribution of repair patches relative to free DNA domains in poly(ADP-ribose)-depleted and undepleted hepatocytes. Parenchymal liver cells were isolated from adult rat hepatocytes and cultured for $24 \mathrm{~h}$ in the presence or absence of $8 \mathrm{mM}$ benzamide as previously described $(9,31)$. The level of chromatin-bound poly(ADP-ribose) in benzamide-treated cells was $<10$ fmol ADP-ribosyl residues $/ 10^{6}$ cells, as determined by the method of Jacobson and co-workers $(32,33)$. Hepatocytes were then exposed to $50 \mu \mathrm{M} N$-acetoxy-2-acetylaminofluorene (NCl Chemical Carcinogen Repository, Bethesda, MD, USA) and newly synthesized repair patches were pulse-labeled with [methyl- ${ }^{3} \mathrm{H}$ ]thymidine $(49 \mathrm{Ci} / \mathrm{mmol}, 20 \mu \mathrm{Ci} / 3 \mathrm{~m}$ l medium) for $20 \mathrm{~min}$. Incorporation of radioactivity was stopped by two changes of medium containing $1.2 \mu \mathrm{M}$ unlabeled thymidine, followed by a chase in the continuous presence or absence of benzamide. At the end of these incubations, free DNA domains were isolated from hepatocellular chromatin as previously described (9) and analyzed for their content of repair patches (9). The numbers plotted on the abscissa represent the ratios of radioactivity (d.p.m./ $\mu$ g DNA) incorporated into free DNA to the radioactivity incorporated into bulk DNA. The values reflect the relative accumulation of repair patches in free DNA (9) (a value of 1 indicates no accumulation) and represent the mean \pm SEM of four independent experiments with separate cell preparations. The overall repair incorporation was $511.2 \pm 85.4 \mathrm{mmol}$ (controls) and $408.2 \pm 94.8 \mathrm{mmol}$ (depleted cells) [methyl- ${ }^{3} \mathrm{H}$ ] thymidine/mol adduct formed (mean $\pm \mathrm{SEM}, n=3$ ). Black bars: control cells; shaded bars: poly(ADP-ribose)-depleted cells. 


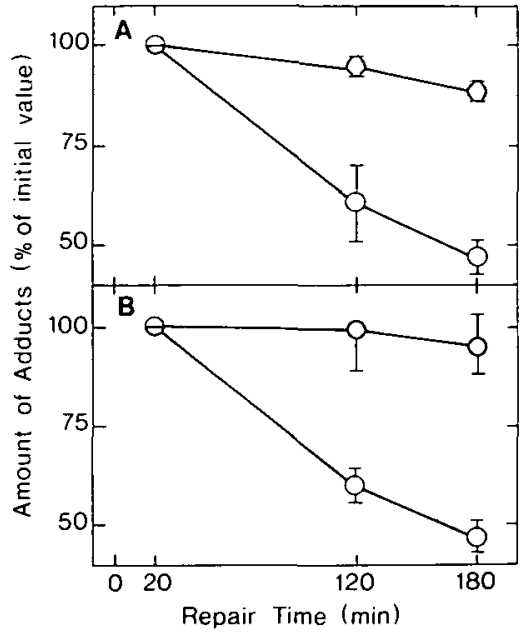

Fig. 2. Excision of deoxyguanosine adducts in total DNA and free DNA domains of poly(ADP-ribose)-depleted and undepleted hepatocytes exposed to $N$-acetoxy-2-acetylaminofluorene (AAAF). Hepatocytes were incubated for 20 min with [G- $\left.{ }^{3} \mathrm{H}\right]$ AAAF $(232 \mathrm{mCi} / \mathrm{mmol}$, total concentration $50 \mu \mathrm{M})$ and the amount of deoxyguanosine adducts was quantified following DNA purification (9). (A) Adduct removal in total DNA; (B) adduct removal in free DNA domains. $0_{-} 0$, poly(ADP-ribose)-depleted cells; $\mathrm{O}_{-} \mathrm{O}$, undepleted control cells. The results represent the means \pm SEM of three independent experiments involving separate cell preparations.

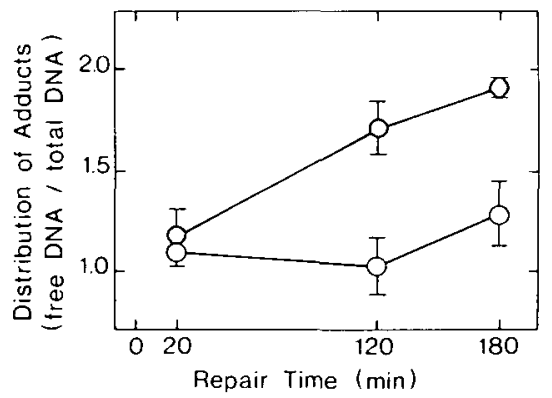

Fig. 3. Relative distribution of the remaining adducts in free DNA domains of poly(ADP-ribose)-depleted and undepleted hepatocytes after various repair intervals. Hepatocytes were incubated with radiolabeled $\mathrm{N}$-acetoxy-2-acetylaminofluorene as described in Figure 2 and the deoxyguanosine adduct concentration was quantified in free DNA and expressed relative to their content in total DNA. $0-0$, poly(ADP-ribose)-depleted cells; $\mathrm{O}-\mathrm{O}$, undepleted cells. The values ploted on the ordinate represent the ratios of [G- $\left.{ }^{3} \mathrm{H}\right] \mathrm{AAAF}$ radioactivity in free DNA to the radioactivity contained in bulk DNA. The results represent the means \pm SEM of three independent experiments involving separate cell preparations.

repair, the rate of excision of deoxyguanosine adducts formed during a $20 \mathrm{~min}$ incubation of hepatocytes with $\mathrm{N}$-acetoxy2-acetylaminofluorene was almost identical in total chromatin and free DNA. However, no excision of these adducts occurred during the same time period in poly(ADP-ribose)-depleted cells (Figure 2). Hence the repositioning of repair patches (Figure 1) seems to be coupled with adduct excision (Figure 2) by a mechanism involving de novo poly ADP-ribosylation of chromatin proteins. This is compatible with the idea that unfolded DNA domains are a preferential site of excision activity (Figure 2).

The results in Figure 3 suggest that some unfolding of chromatin occurs also in poly(ADP-ribose)-depleted cells. A slight accumulation of unexcised DNA adducts in the free DNA fraction was obtained in poly(ADP-ribose)-depleted cells, while no significant accumulation was seen in undepleted control cells. Thus, the unfolded domains formed in poly(ADP-ribose)-depleted cells are enriched in DNA adducts and largely deficient in repair patches (cf. Figures 1 and 3).

Our results thus reveal a tight functional linkage between structural chromatin rearrangements and the excision step, and dissect the process of repair patch synthesis from the patch repositioning relative to nucleosomally organized chromatin regions. Moreover, our results tentatively identify a requirement for poly ADP-ribosylation in co-ordinating excision repair with structural rearrangements of chromatin. The role of this posttranslational protein modification is poorly understood, but all protein acceptors of poly(ADP-ribose) hitherto identified (for review see 4) share the capacity to bind to nucleic acids. Poly ADP-ribosylation of these proteins in vitro reversibly alters their DNA binding affinity $(10-15)$. Enzymatic addition and removal of ADP-ribose polymers on chromatin preparations in vitro induces reversible relaxation of polynucleosomes (16), the relaxation state being directly related to the size of histone-bound ADP-ribosyl polymers (17-19). Histones are also a physiological target of ADP-ribose modifications in carcinogen-treated mammalian cells in vivo $(20,21)$. Thus, the reversible modification of DNA - protein interactions $(14,15,22,23)$ by protein ADP-ribosylation may be the underlying molecular mechanism for the transient formation of free DNA domains in eukaryotic excision repair.

As far as our findings ascribe poly ADP-ribosylation a role in DNA excision repair, they contrast the hypothesis of Shall and associates who envisioned poly ADP-ribosylation as a direct regulatory mechanism of ligation activity in the repair of alkylation damage in DNA $(24,25)$. However, other reports could not confirm such a role for poly(ADP-ribose) in DNA excision repair $(26-30)$. This contradictory phenomenology may be reconciled on the premise that poly ADP-ribosylation affects local disruptions of chromatin structure and this secondarily affects DNA repair reactions $(4,26-30)$.

\section{Acknowledgements}

We thank Phyllis Panzeter for critically reviewing this manuscript. This work was supported by grant 3.161.088 from the Swiss National Foundation for Scientific Research, and the Jubiläumsstiftung of the University of Zürich.

\section{References}

I. Friedberg,E.C. (1985) DNA Repair. W.H.Freeman, New York.

2. Smerdon,M.J. (1990) In Lambert,M.W. and Laval,J. (eds), DNA Repair Mechanisms and their Biological Implications in Mammalian Cells. Plenum, New York, pp. in press.

3. Ueda,K. and Hayaishi,O. (1985) ADP-ribosylation. Annu. Rev. Biochem. 54, $73-100$.

4. Althaus,F.R. and Richter,C. (1987) Molecular Biology, Biochemistry, and Biophysics, Vol. 37: ADP-ribosylation of Proteins: Enzymology and Biological Significance. Springer-Verlag, Berlin.

5. Naegeli,H. and Althaus,F.R. (1989) Poly ADP-ribosylation of proteins: processivity of a posttranslational modification. J. Biol. Chem., 264, $14382-14385$.

6. Rankin,P.W., Jacobson,E.L., Benjamin, R.C., Moss,J. and Jacobson,M.K. (1989) Quantitative studies of inhibitors of ADP-ribosylation in vitro and in vivo. J. Biol. Chem., 264, 4312-4317.

7. Alvarez-Gonzalez,R. and Althaus,F.R. (1989) Poly(ADP-ribose)catabolism in mammalian cells exposed to DNA-damaging agents. Mutat. Res., 218, $67-74$

8. Althaus,F.R., Lawrence,S.D., He,Y.Z., Sattler,G.L., Tsukada,Y. and Pitot,H.C. (1982) Effects of altered [ADP-ribose $]_{n}$ metabolism on expression of fetal functions by adult rat hepatocytes. Nature, 300, 366-368.

9. Mathis,G. and Althaus,F.R. (1986) Periodic changes of chromatin organization associated with rearrangement of repair patches accompanying DNA excision repair of mammalian cells. J. Biol. Chem., 261, 5758-5765.

10. Gaal,J.C. and Pearson,C.K. (1985) Eukaryotic nuclear ADP-ribosylation reactions. Biochem. J., 230, 1-18. 
11. Burzio,L.O., Koide,S.S., Puigdomenech,P. and Ruiz-Carrillo,A. (1980) ADPribosylation of rat liver $\mathrm{H} 1$ and nucleosomal core histones. In Smulson,M.E. and Sugimura, T. (eds), Novel ADP-ribosylations of Regulatory Enzymes and Proteins. Elsevier/North Holland, New York, pp. 345-356.

12. Yoshihara,K., Hashida,T., Tanaka,Y., Matsunami,N., Yamaguchi, A. and Kamiya,T. (1981) Mode of enzyme-bound poly(ADP-ribose) synthesis and histone modification by reconstituted poly(ADP-ribose)polymerase-DNA cellulose complex. J. Biol. Chem., 256, 3471-3478.

13. Ohashi,Y.J. (1986) Effect of ionic strength on chain elongation in ADPribosylation of various nucleases. J. Biochem., 99, 971-979.

14. Ferro,A.M. and Olivera,B.M. (1982) Poly(ADP-ribosylation) in vitro. Reaction parameters and enzyme mechanism. J. Biol. Chem., 257, 7808-7813.

15. Zahradka,P. and Ebisuzaki,K. (1982) A shuttle mechanism for DNA-protein interactions. The regulation of poly(ADP-ribose)polymerase. Eur. J. Biochem., 127, 579-585.

16. De Murcia,G., Huletsky,A., Lamarre,D., Gaudreau,A., Pouyet,J., Daune,M. and Poirier,G.G. (1986) Modulation of chromatin superstructure induced by poly(ADP-ribose) synthesis and degradation. J. Biol. Chem., 261, 7011-7018.

17. Butt,T.R. and Smulson,M. (1980) Relationship between nicotinamide adenine dinucleotide concentration and in vitro synthesis of poly(adenosine diphosphate ribose) on purified nucleosomes. Biochemistry, 19, 5233-5242.

18. Aubin,R.J., Frechette,A., de Murcia,G., Mandel,P., Lord,A., Grondin,G. and Poirier,G.G. (1983) Correlation between endogenous nucleosomal hyper(ADP-ribosyl)ation of histone $\mathrm{H} 1$ and the induction of chromatin relaxation. EMBO J., 2, 1685-1693.

19. Huletsky,A., De Murcia,G., Muller,S., Hengartner,M., Ménard,L., Lamarre,D. and Poirier,G.G. (1989) The effect of poly(ADP-ribosyl)ation on native and $\mathrm{H} 1$-depleted chromatin. J. Biol. Chem., 264, 8878-8886.

20. Kreimeyer,A., Wielckens,K., Adamietz,P. and Hilz,H. (1984) DNA repairassociated ADP-ribosylation in vivo. J. Biol. Chem., 259, 890-896.

21. Adamietz,P. and Rudolph,A. (1984) ADP-ribosylation of nuclear proteins in vivo. Identification of histone $\mathrm{H} 2 \mathrm{~B}$ as a major acceptor for mono- and poly(ADP-ribose) in dimethyl sulfate-treated hepatoma AH 7974 cells. J. Biol. Chem., 259, 6841-6846.

22. Mathis,G. and Althaus,F.R. (1987) Release of core DNA from nucleosomal

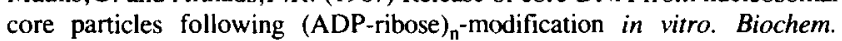
Biophys. Res. Commun., 143, 1049-1053.

23. Althaus,F.R., Collinge,M., Loetscher,P., Mathis,G., Naegeli,H., Panzeter,P. and Realini,C. (1990) The poly ADP-ribosylation system of higher eukaryotes: how can it do what? Adv. Mutagen. Res., 1, 22-30.

24. Creissen,D. and Shall,S. (1982) Regulation of DNA ligase activity by poly(ADP-ribose). Nature, 296, 271-272.

25. Shall,S. (1989) ADP-ribosylation of proteins: a ubiquitous cellular control mechanism. Biochem. Soc. Trans., 17, 317-322.

26. Ohashi, Y., Ueda,K., Kawaichi,M. and Hayaishi,O. (1983) Activation of DNA ligase by poly(ADP-ribose) in chromatin. Proc. Natl. Acad. Sci. USA, 80, 3604-3607.

27. Moran,M.F. and Ebisuzaki,K. (1985) Inhibition of poly(ADP-ribose)polymerase causes increased DNA strand breaks without decreasing strand rejoining in alkylated HeLa cells. FEBS Lett., 190, 279-282.

28. Morgan,W.F., Djordjevic,M.C., Milam,K.M., Schwartz,J.L., Borek,C. and Cleaver,J.E. (1985) Is there a role for ADP-ribosylation in DNA repair? In Althaus,F.R., Hilz,H. and Shall,S. (eds), ADP-ribosylation of Proteins. Springer-Verlag, Berlin, pp. 244-251.

29. Cleaver,J.E. and Park,S.D. (1986) Enhanced ligation of repair sites under conditions of inhibition of poly(ADP-ribose) synthesis by 3-aminobenzamide. Mutat. Res., 173, 287-290.

30. Teraoka,H., Sumikawa,T. and Tsukada,K. (1986) Purification of DNA ligase II from calf thymus and preparation of rabbit antibody against calf thymus DNA ligase II. J. Biol. Chem., 259, 6888-6892.

31. Althaus,F.R., Lawrence,S.D., Sattler,G.L. and Pitot,H.C. (1982) ADPribosyltranferase activity in cultured hepatocytes: interactions with DNA repair J. Biol. Chem., 257, 5528-5535.

32. Jacobson,M.K., Payne,D.M., Alvarez-Gonzalez,R., Juarez-Salinas,H., Sims,J.L. and Jacobson,E.L. (1984) Determination of in vivo levels of polymeric and monomeric ADP-ribose by fluorescence methods. Methods Enzymol, 106, 483-494.

33. Alvarez-Gonzalez,R., Eichenberger,R., Loetscher,P. and Althaus,F.R. (1986) A new highly selective physicochemical assay to measure $\mathrm{NAD}^{+}$in intact cells. Anal Biochem., 156, 473-480.

Received on February 7. 1990; revised on April 4, 1990; accepted on April 9, 1990 